\title{
Calculating an electromechanical torque of a squirrel cage motor based on an axial flux obtained by the FEM
}

\author{
Janusz Petryna ${ }^{1}$, Jarosław Tulicki ${ }^{1}$, and Maciej Sułowicz ${ }^{1, *}$ \\ ${ }^{1}$ Cracow University of Technology, Faculty of Electrical and Computer Engineering, Institute of Electromechanical Energy Conversion, \\ Warszawska Street 24, 31-155 Cracow, Poland
}

\begin{abstract}
This article presents a method of calculating an axial flux signal and how to use this signal to determine an electromagnetic torque for a squirrel cage induction motor in a steady state. Numerical analyses were performed using a two-dimensional field-circuit model for the squirrel cage induction motor. Most of analyses were performed for a symmetric motor and to estimate a magnitude of the electromagnetic torque, an algorithm was developed. The electromagnetic torque estimation method proposed in the article is easy to implement and does not require any interference into the drive system transmission. The analysis shows that it is possible for the induction motor to determine a load torque based on the axial flux measurement using a measuring coil applied to the motor, for example from the fan side.
\end{abstract}

\section{Introduction}

One of commonly used diagnostic signals in evaluating the condition of induction motors is the axial flux. This signal is easily measurable and allows to extract many useful information about the condition of the machine itself and about the efficiency of the electric power conversion by this machine [1-17].

One of ways to install a coil for the axial flux measurement is shown in Fig. 1.

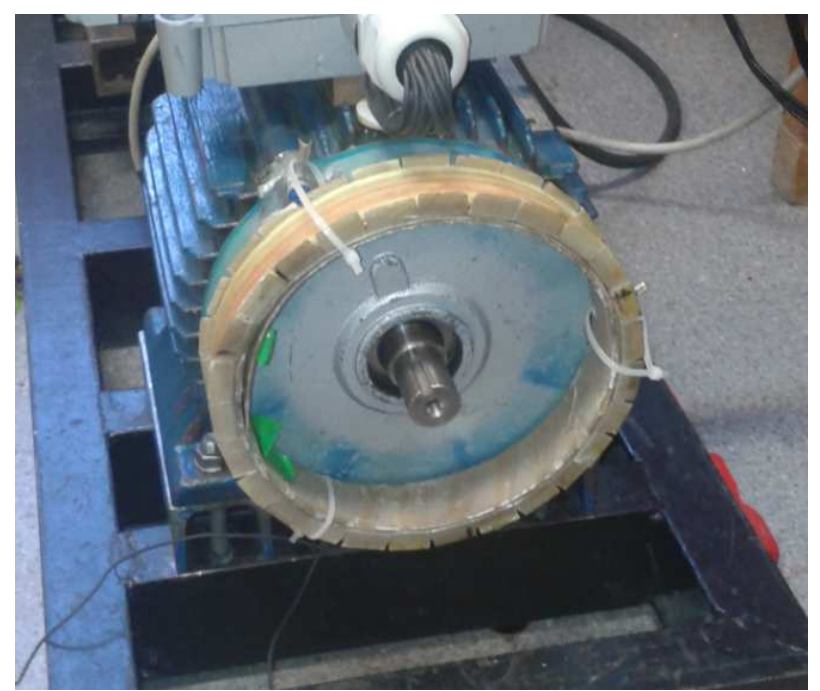

Fig. 1. Method of axial flux measurement.

A coreless coil is a basic element used to capture changes in unipolar flux as a function of time. The winding direction of this coil is perpendicular to the main axis of the machine. The coil acts as a secondary winding, in which the voltage is induced by the motor alternating the flux. The flux instantaneous value is directly proportional to the induced voltage on the coil terminals. From the above, it results that the main metrological feature of the air coil is the lack of nonlinear signal distortion and the characteristic similar to the band-pass filter. In terms of mechanical construction, the most important parameter is the diameter of the carcass, which should not be less than the diameter of the rotor cage and greater than the internal diameter of the stator.

In laboratory and industrial practice, the measurement coil may be located on the non-drive side of the fan cover [16] or on the driving side inside of the bearing disk [14, 15], less frequently on the stator body. This axial flux signal can just be used in many ways, both for the diagnosis of the machine condition itself and for determining the rotational speed or torque of the motor shaft. In an ideal induction machine, axial flux should not be present. In fact, around the stator end windings and around the ring segments of the cage, flux of axial direction occurs.

Moreover, both in the stator and rotor circuits, various types of asymmetries due to geometrical inaccuracies in the distribution of windings or nonhomogeneity of materials appear. As a result of this type of inaccuracy in the machine, small but noticeable axial flux is produced. The necessary conditions for the formation of axial flow through numerical analyzes are given in papers $[2,5,7]$.

Accurate determination of axial flux time course is fully possible on the basis of the solution of the fieldcircuit equations of the three-dimensional model. An example of such a model with a measuring coil assembled is shown in Fig. 2.

* Corresponding author: msulowicz@pk.edu.pl 


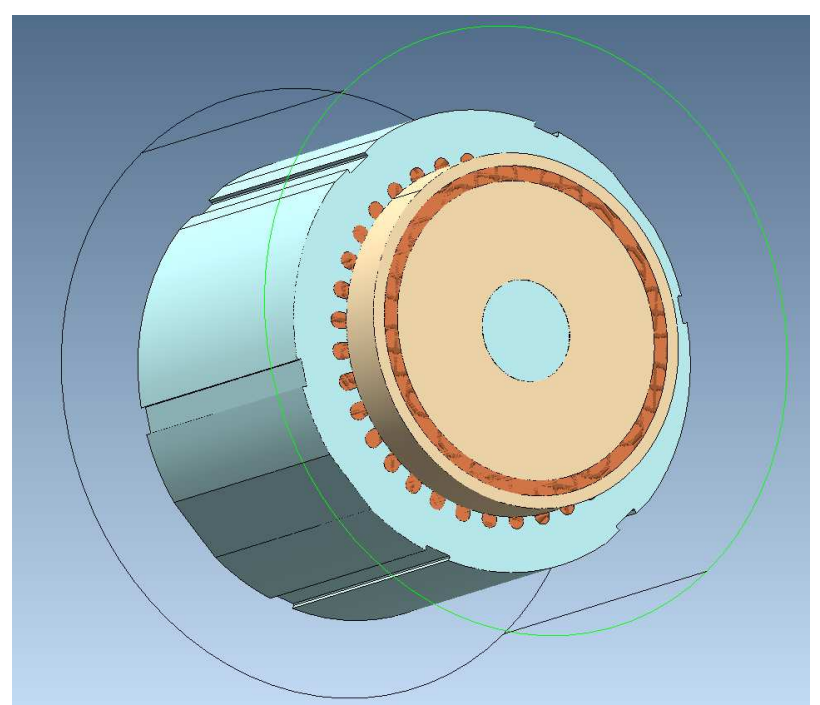

Fig. 2. The 3D field model of the motor with a measuring coil located at the end winding front.

This approach allows to define quantitative and qualitative character of the leakage flux waveforms in the shaft axis inside the motor.

With some simplifications [15], a 2D model can be used to determine the axial flux. In the following section, the application of the 2D model to determine the relationship between the axial flux signal and the load torque will be described. This relationship is extremely significant to develop a method for estimating the load torque of a machine based on the measurement of the axial flow only.

\section{The 2D FEM model description}

The field-and-circuit model was built on the basis of a deep-slotted Sg-112M low-power induction motor with two pairs of poles. The motor has a single-layer winding with a diametral winding pitch. Stator yoke geometry included an actual shape of the magnetic core with the assembly points of the machine body (the sheets do not have a circular shape as it is assumed in typical FEM models). Each slot of the stator yoke was divided between areas filled with winding copper wires and the surface covered by the wedge. The rotor cage bars are made as a cast of pure aluminum. Included in the geometric design of the rotor are also additional elements such as: an air-filled ventilation duct and a rotor shaft made of the machinery steel. Material of the stator and rotor cores were packed was the MU1000 type material of the linear characteristics. Due to the lack of possibility of including the stator and rotor end windings in the two-dimensional model, the stator end windings and cage end rings were included in the circuit part of the model. The above winding elements whose leakage fluxes are closed by the air, are defined as the passive RL two-terminal units. The accepted model of the motor does not take into account the rotor slots skew. For the purpose of calculations, it was set up that the maximum distance between the finite elements mesh points is $1.5 \mathrm{~mm}$. The simulation time was $10 \mathrm{~s}$ at the integration step of $0.5 \mathrm{~ms}$. The field-circuit $2 \mathrm{D}$ model of the induction motor was developed with use of the MagNet software. The following figures show the 2D model of the motor for which the calculations were performed (Fig. 3.), and the FEM grid for the entire rotor cross-section (Fig. 4.) and quarters of this model (Fig. 5.).

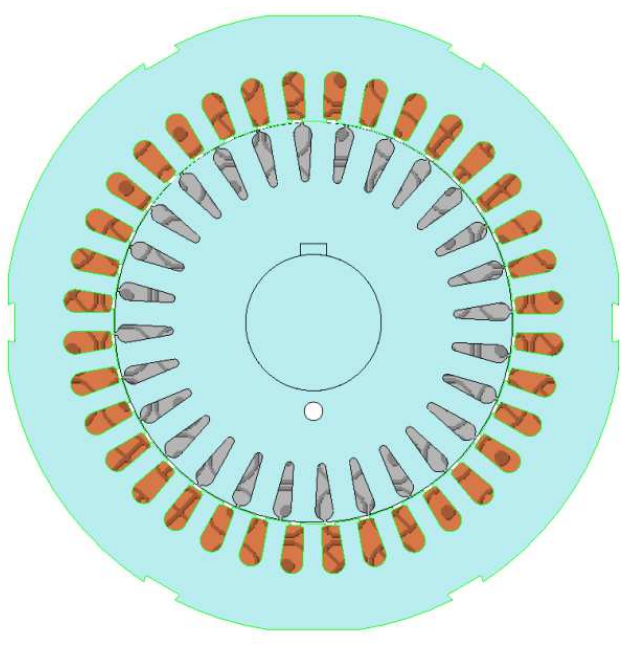

Fig. 3. The 2D model of the tested motor - main view.

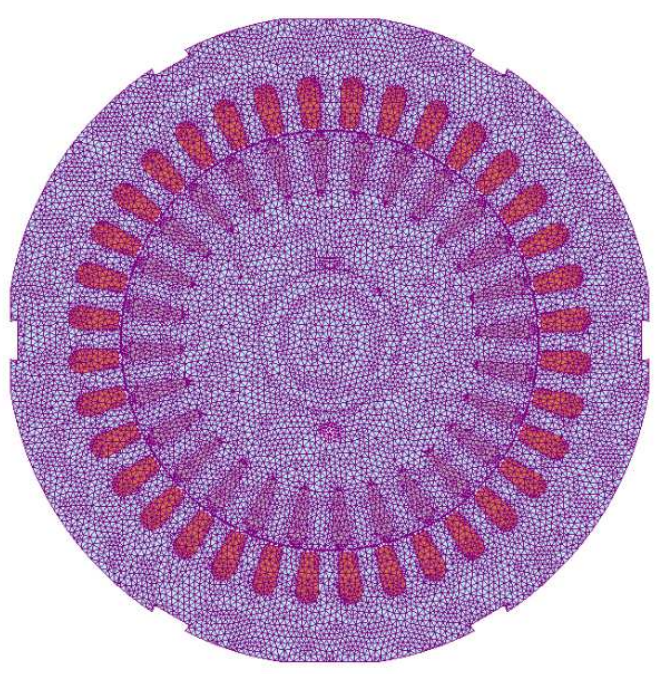

Fig. 4. The FEM grid for the complete 2D model.

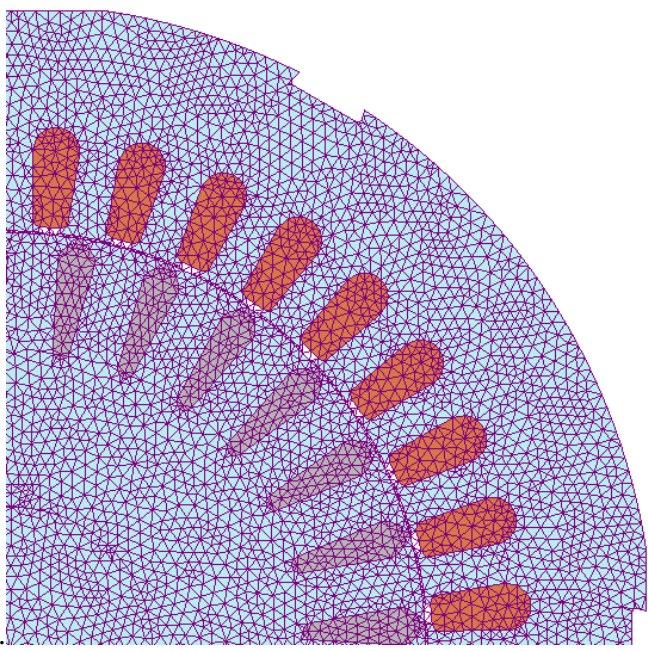

Fig. 5. The quarter of the FEM grid. 
On the basis of the model described above, stator currents, rotor currents, currents in the joint rings segments, the voltage patterns on the stator windings and the electromagnetic torque are determined.

In the following part, the methodology for calculating the axial flux for the symmetrical motor is presented, with some imperfections in the rotor cage execution and negligible resistance asymmetry in the stator windings, being assumed.

\section{Method of calculating the axial flux signal and its analysis}

When calculating the axial flux signal, it was assumed that it was generated because of small asymmetries in the stator and rotor windings.

A two-dimensional FEM model was taken for the calculations, and it was assumed that the resulting waveform of the axial flux was a superposition of the stator and rotor fluxes. It can be described by the formula:

$$
\Psi^{0}(t)=\sum_{n=1}^{m_{s}} \Psi_{n}^{s}(t)+\sum_{k=1}^{N_{r}} \Psi_{k}^{r}(t)
$$

where: $\Psi^{0}-$ axial flux, $\Psi^{s}-$ stator winding leakage flux, $\Psi^{r}$ - leakage flux of the rotor joint ring segment, $m_{s}$ - stator number of phases; $N_{r}$ - rotor bars number.

It was assumed that the stator flux is produced by the end winding front connections. In turn, the flux of the rotor origin is associated with the joint rings segments.

In the axial flow calculation for the stator, $2.5 \%$ difference in the resistance of the individual phases was assumed.

The individual phase currents values were multiplied by the coefficients to obtain the asymmetry of the currents. The 1.025 coefficient was applied for L1phase, 0.975 for L2 phase and 1 for L3 phase.

The value of the leakage inductance was estimated. In further calculations, the value of $L_{s r}=1.83 * 10^{-5} \mathrm{H}$ was assumed.

The axial flux signal generated by the stator can be written as follows:

$$
\Psi^{s}(t)=\sum_{n=1}^{m_{s}} I_{n}^{s}(t) \cdot L_{r s}
$$

Similarly, the time course of the axial flux from the rotor can be calculated as:

$$
\Psi^{r}(t)=\sum_{k=1}^{N_{r}} \Psi_{k}^{r}(t) \cdot L_{r r}
$$

The leakage inductance value was determined. In further calculations, the value $L_{r r}=3.63 * 10^{-9} \mathrm{H}$ was assumed.

The instantaneous value of the induced voltage in the measuring coil is expressed as a derivative of the axial flow over time:

$$
e(t)=-N \frac{d}{d t} \phi^{0}=-\frac{d}{d t} \Psi^{0}(t)
$$

where: $e(t)$ - voltage induced in the measuring coil, $N$ proportional factor (number of turns of measurement coil).

All the following waveforms of stator windings, currents in the rotor cage bars and currents in the segments of the cage joint rings, the electromagnetic torque and the rotational speed of the rotor were calculated on the basis of the 2D model. The calculation included a symmetrical stator circuit, a symmetrical rotor cage, symmetrical $230 \mathrm{~V}$ power supply, a torque load of $7 \mathrm{Nm}$, and an average established speed of $1459 \mathrm{rpm}$.

Calculations were proceeded from the moment when the motor was switched on until the speed was established. Apart from the $7 \mathrm{Nm}$ load, simulations were performed for $8,9,10,11 \mathrm{Nm}$. An example of a current waveform in a segment of a cage joint ring is shown in Fig. 6.

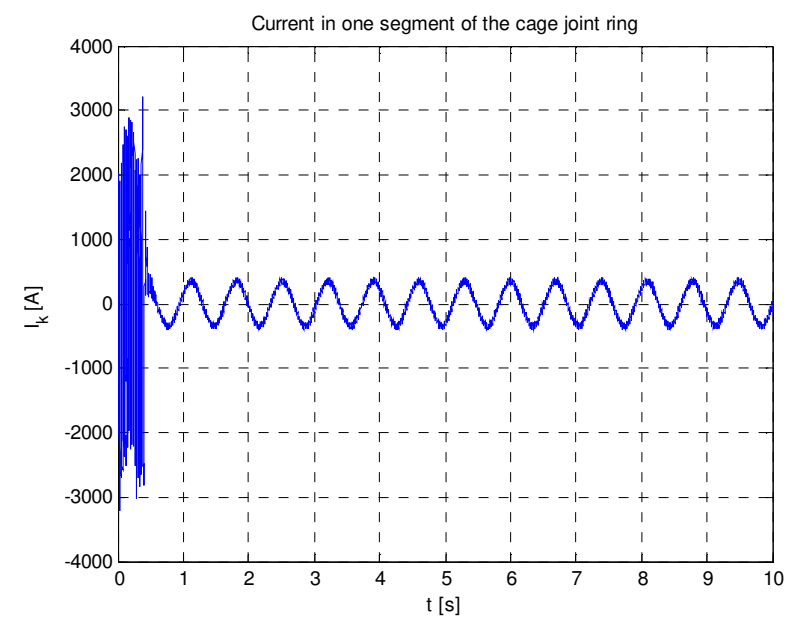

Fig. 6. Current waveform in 1 segment of the cage joint ring.

Fig. 7. shows the current waveform in the winding of the first stator phase and Fig. 8. - current waveform in 1 bar of the rotor cage.

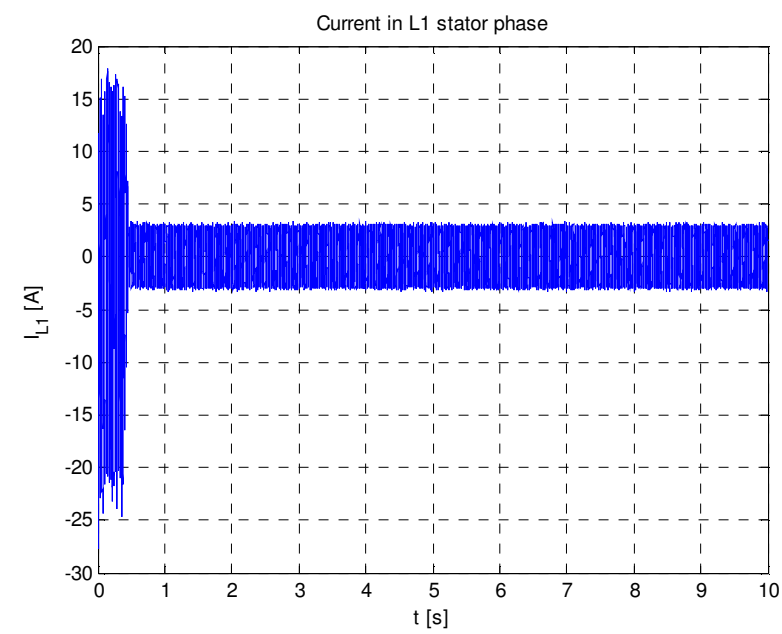

Fig. 7. Current waveform in the winding of the first stator phase. 


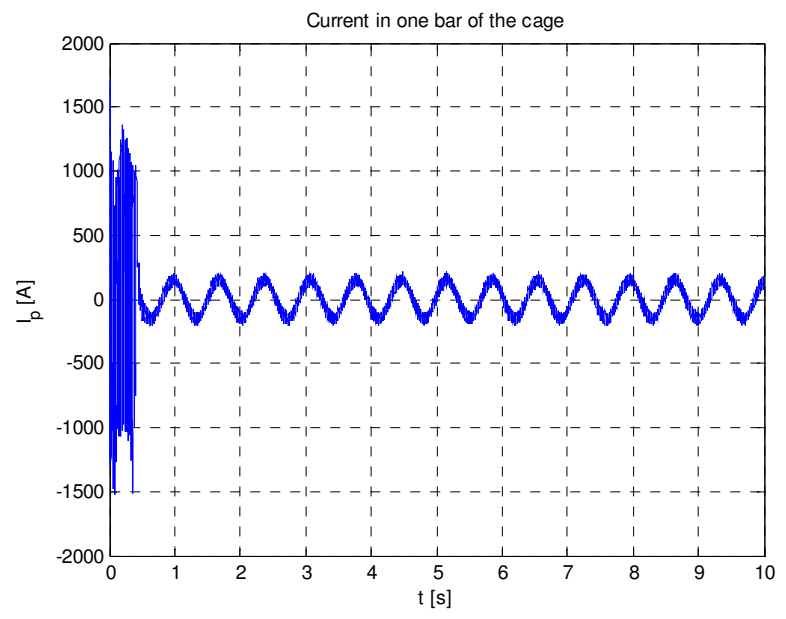

Fig. 8. Current waveform in 1 bar of the rotor cage.

The calculated axial flux according to formula (1) and the coil voltage based on formula (4) are shown in Fig. 9. to Fig. 11.

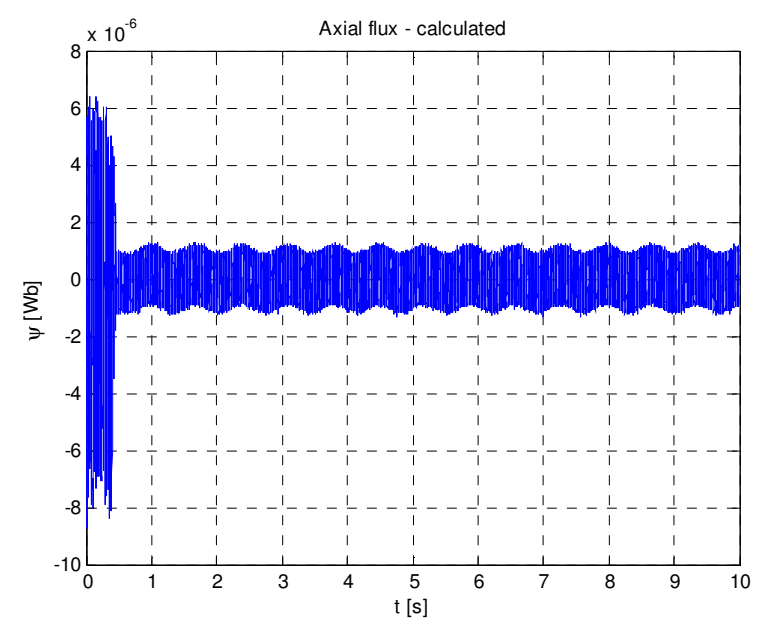

Fig. 9. The waveform of the calculated axial flux.

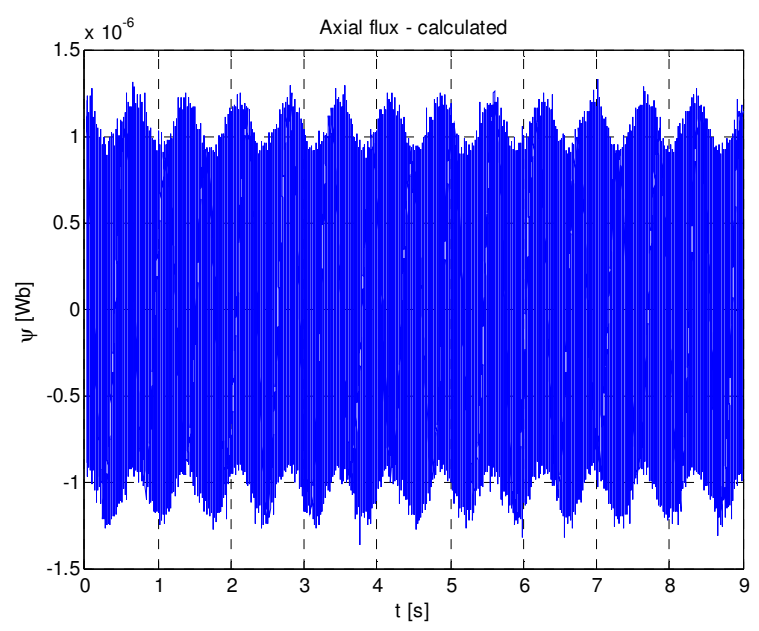

Fig. 10. The waveform of the calculated axial flux - steady state.

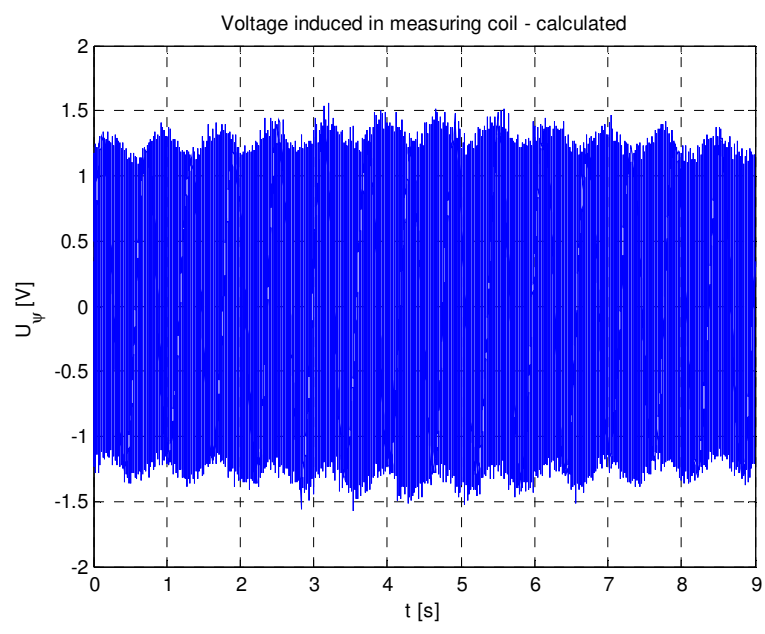

Fig. 11. The waveform of induced voltage in the coil - steady state.

Further analyses will consider the steady state signals of the machine operation. The amplitude spectra of the axial flux and its derivative are shown in Fig. 12. and Fig. 13. Fig. 14. and Fig. 15. present respectively the spectra of these both signals calibrated in $\mathrm{dB}$.

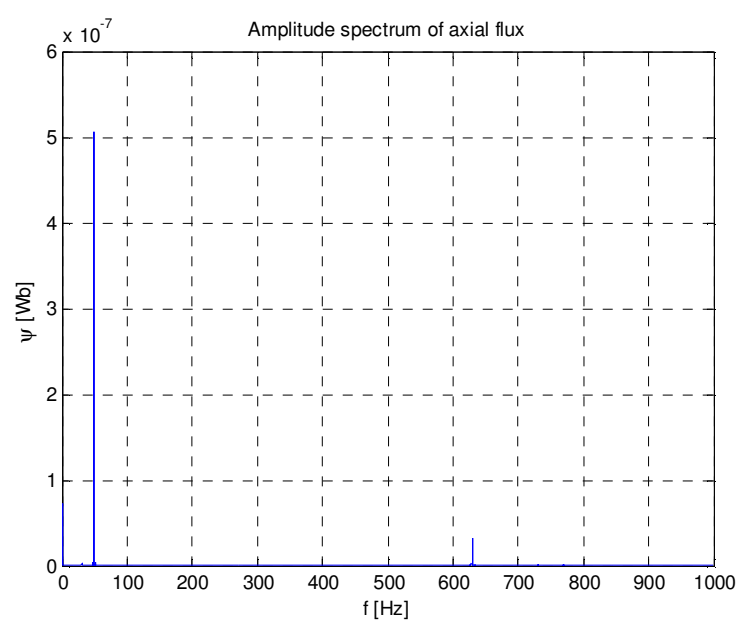

Fig. 12. Amplitude spectrum of the axial flux.

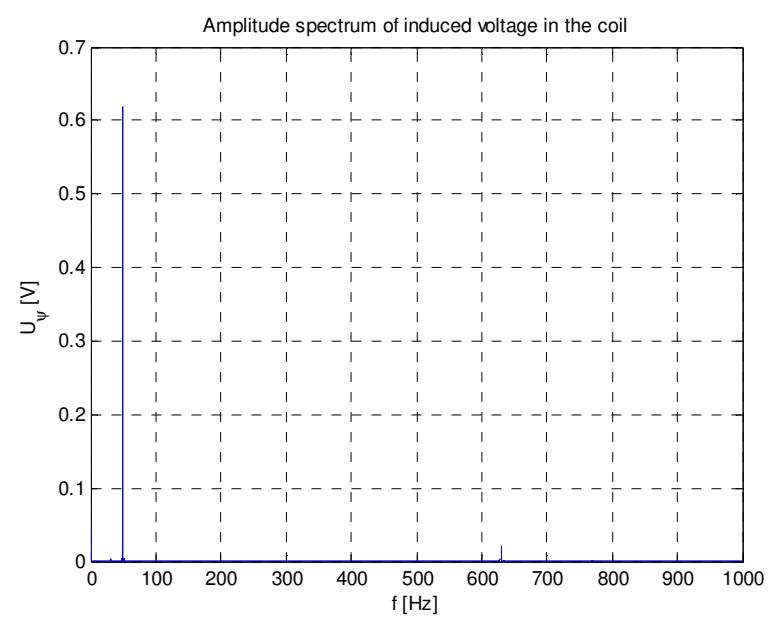

Fig. 13. Amplitude spectrum of the axial flux derivative. 


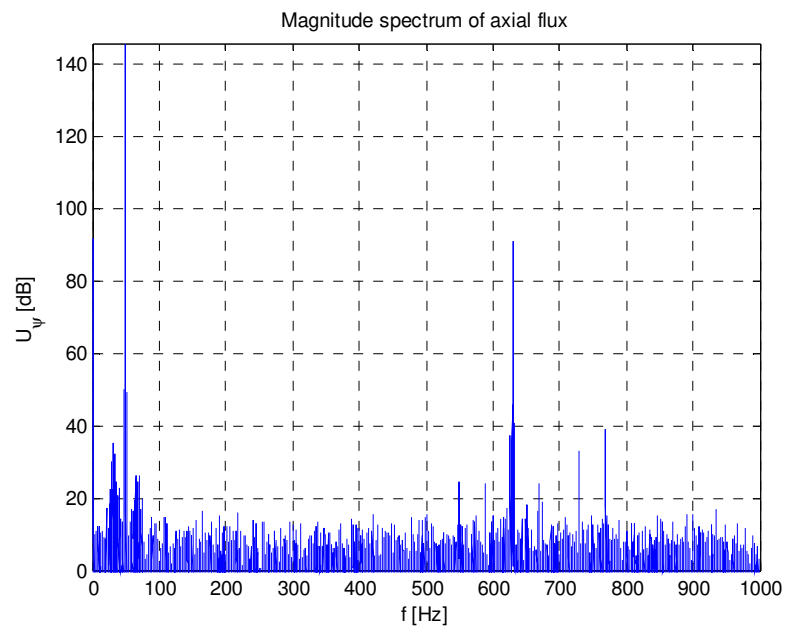

Fig. 14. Magnitude spectrum of the axial flux.

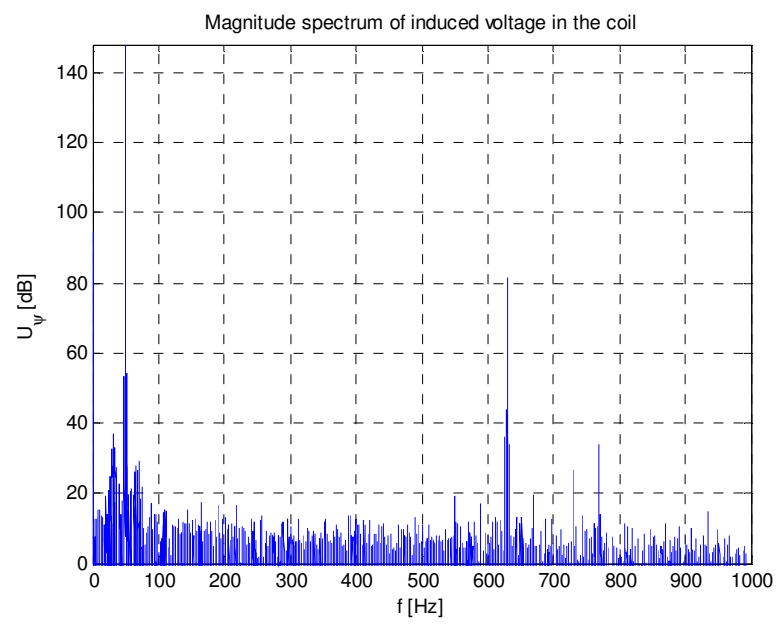

Fig. 15. Magnitude spectrum of the axial flux derivative.

Both in the signal of the axial flux and in its derivative some characteristic features can be noted, which can be uniquely identified as information related to a specific state of the machine.

In order to determine the magnitude of the torque on the basis of the axial flux, the dominant features of the signals from both the stator and rotor will be very important.

In Fig. 14. and Fig. 15, the dominant features as f0, sfo, principal slot harmonic and some additional characteristic frequencies used for diagnostics of the analysed motor, are seen.

\section{Calculation of electromagnetic torque and its analysis}

Directly from the field model, the time waveforms of the electromagnetic torque and the speed signals were calculated. The speed signal will also be useful in the load torque estimation algorithm. The electromagnetic torque and speed signals are shown in Fig. 16. and Fig. 17.

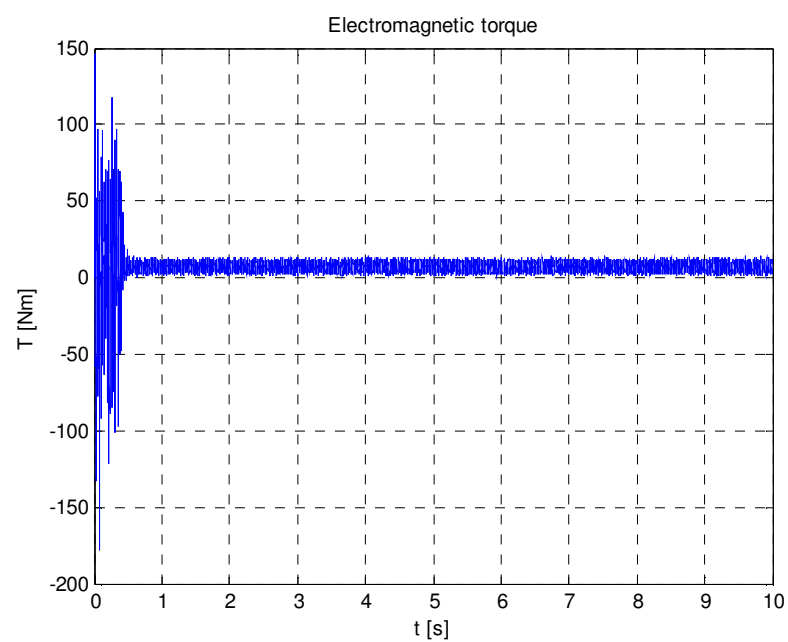

Fig. 16. Electromagnetic torque time course.

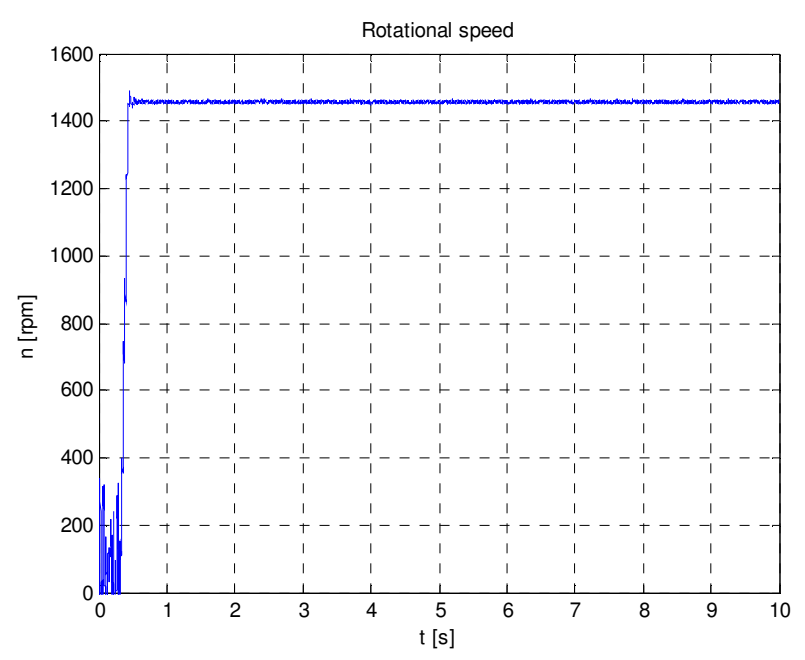

Fig. 17. Rotational speed time course.

As for the axial flux, the electromagnetic torque signal was analysed in steady state. An exemplary torque course in steady state is shown in Fig. 18.

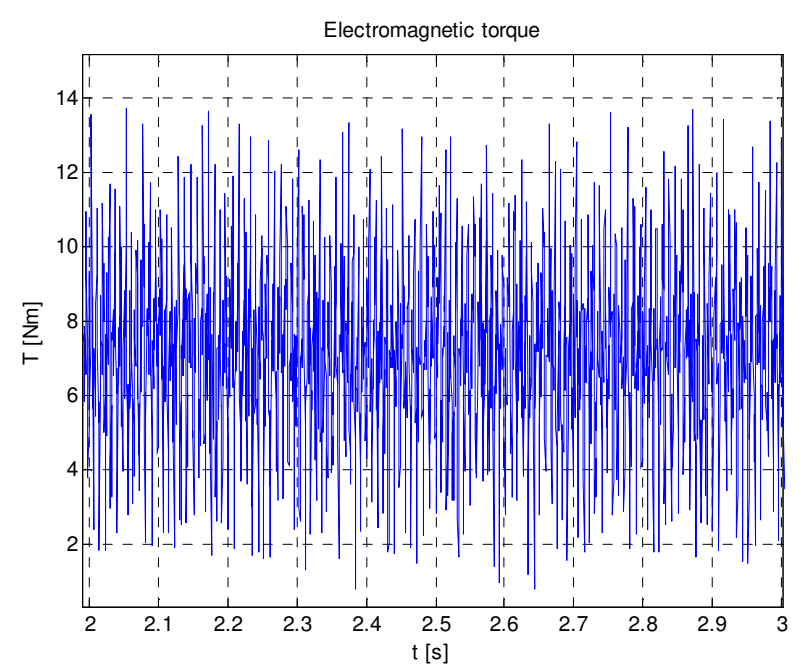

Fig. 18. Time course of the electromagnetic torque enlargement in the interval of 1 second. 
Fig. 19. and Fig. 20. show the amplitude spectra of the electromagnetic torque calibrated respectively in linear and logarithmic scale.

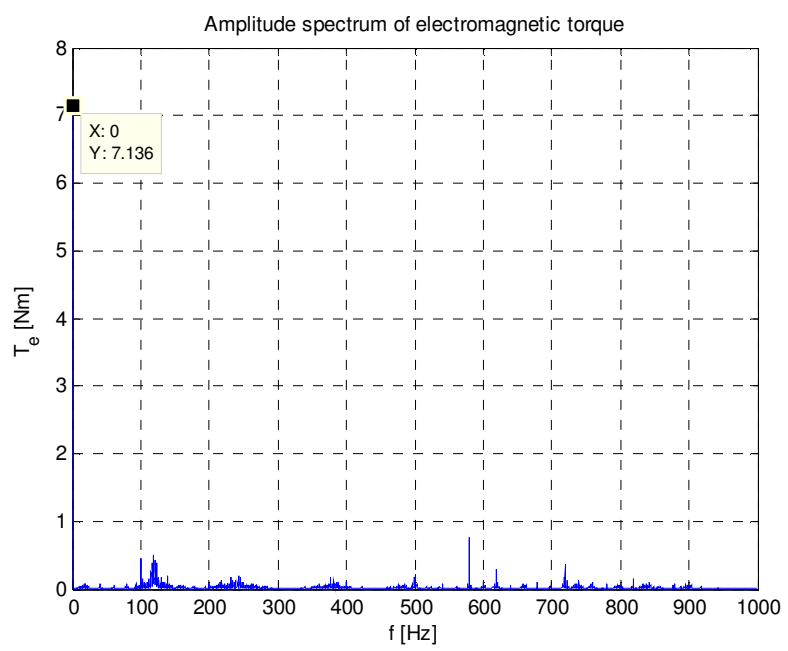

Fig. 19. Amplitude spectrum of electromagnetic torque.

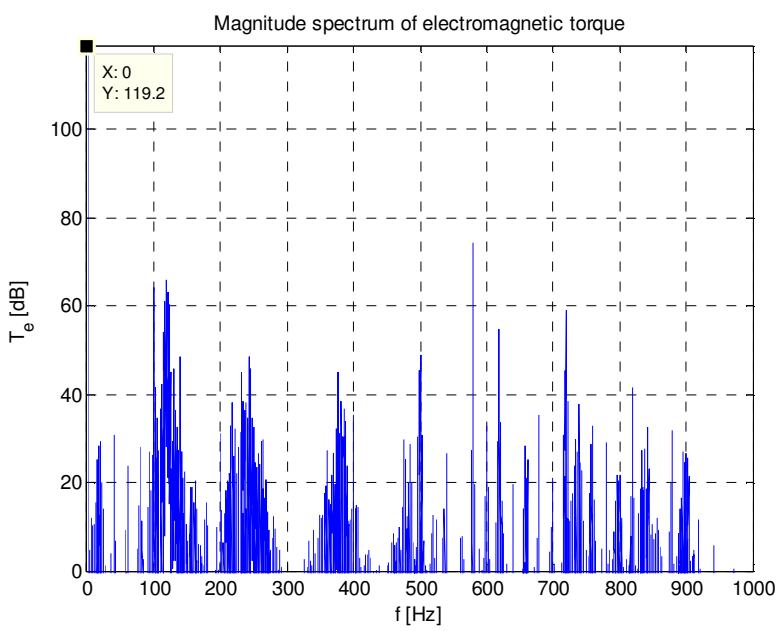

Fig. 20. Magnitude spectrum of electromagnetic torque.

The value of the amplitude of the zero-torque component determined from the time course of the calculated torque signal, will be an important feature in search of the relationship between the axial flow and the electromagnetic torque.

\section{Torque estimation algorithm based on axial flux signal}

The above analyses and developed method of the axial flux analysis allowed to observe and find the relationship between the characteristic features of the axial flux and the electromechanical load torque.

Fig. 21. to Fig. 23. present the characteristic features of the axial flux for the dominant components of the stator and rotor spectrum.

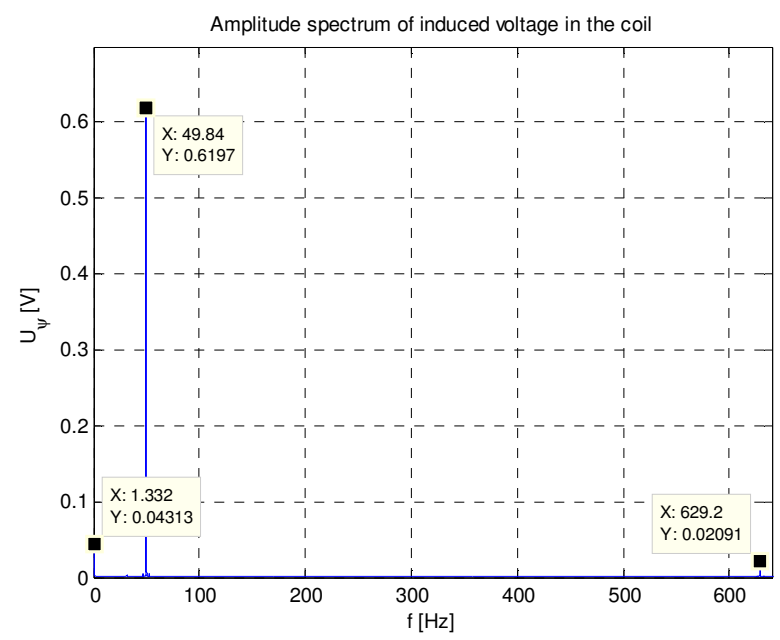

Fig. 21. Spectrum of axial flux - load torque $7 \mathrm{Nm}$, observation window from 0 to $640 \mathrm{~Hz}$.

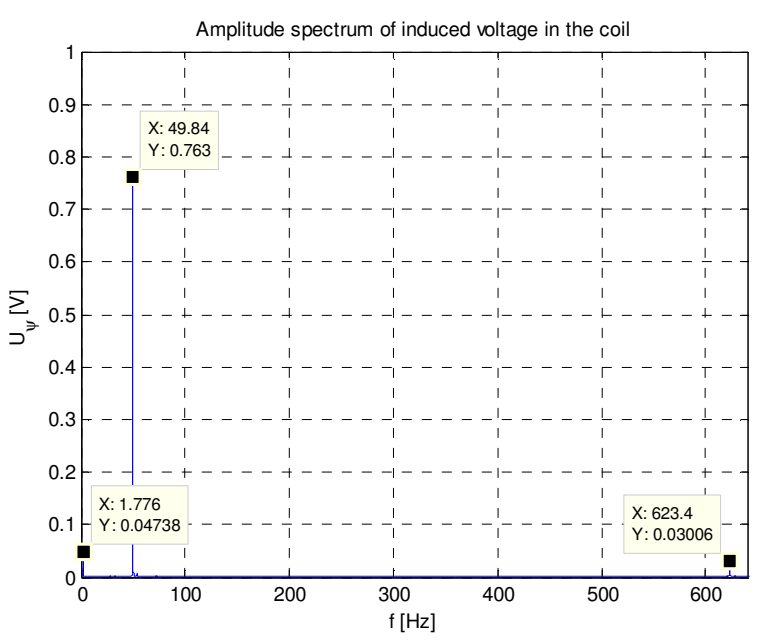

Fig. 22. Spectrum of axial flux - load torque $9 \mathrm{Nm}$, observation window from 0 to $640 \mathrm{~Hz}$.

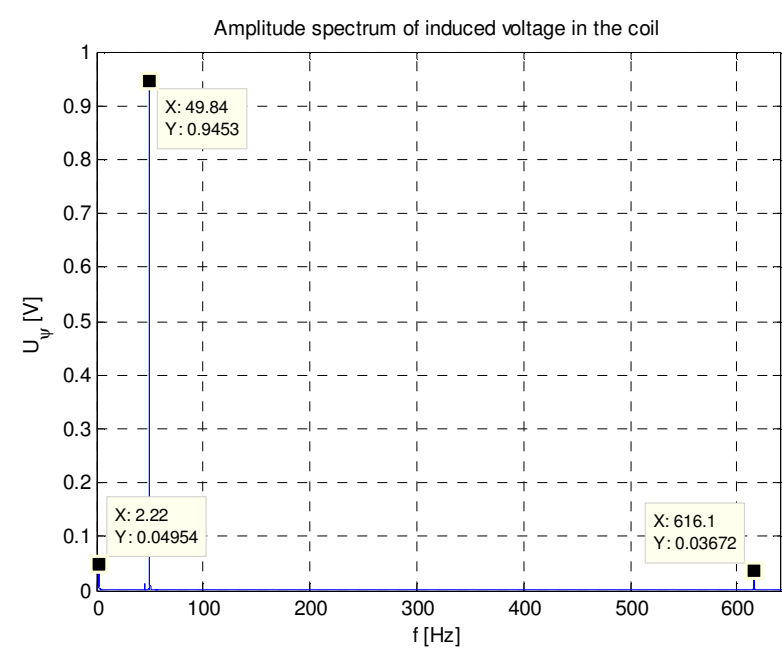

Fig. 23. Spectrum of axial flux - load torque $11 \mathrm{Nm}$, observation window from 0 to $640 \mathrm{~Hz}$.

Table 1 summarizes the values of the characteristic features and torque values obtained on the basis of time courses of the axial flux and the electromagnetic torque. 
Table. 1. List of the characteristic features of the axial flux and the electromagnetic torque.

\begin{tabular}{|c|c|c|c|c|c|}
\hline $\begin{array}{c}\mathrm{T} \\
{[\mathrm{Nm}]}\end{array}$ & $\begin{array}{c}\text { Amp } \\
s^{*} \mathbf{f}_{0} \\
{[\mathbf{V}]} \\
\end{array}$ & $\begin{array}{c}\mathbf{A m p} \\
\mathbf{f}_{0} \\
{[\mathbf{V}]}\end{array}$ & $\begin{array}{c}\text { Amp } \\
\mathbf{f}_{\text {psh }} \\
{[\mathbf{V}]} \\
\end{array}$ & $\begin{array}{c}\text { RMS } \\
{[\text { V] }}\end{array}$ & $\begin{array}{c}\mathbf{T} / \\
\text { Amp } \mathbf{f}_{0} \\
{[-]}\end{array}$ \\
\hline 7.14 & 0.043 & 0.62 & 0.023 & 0.8826 & 11.52 \\
\hline 7.96 & 0.032 & 0.68 & 0.029 & 0.9715 & 11.67 \\
\hline 9.30 & 0.047 & 0.76 & 0.030 & 1.0866 & 12.19 \\
\hline 10.77 & 0.041 & 0.87 & 0.020 & 1.2391 & 12.40 \\
\hline 11.91 & 0.049 & 0.94 & 0.036 & 1.3465 & 12.60 \\
\hline
\end{tabular}

In the table above, the letter signs are entered:

$\mathrm{T}$ - electromagnetic torque read out from the spectrum, $s$-slip,

$\mathrm{f}_{0}$ - frequency of the supply voltage,

$\mathrm{f}_{\mathrm{psh}}$ - principal slot harmonic.

The characteristic calculation points shown in Table 1 are illustrated in Fig. 24.

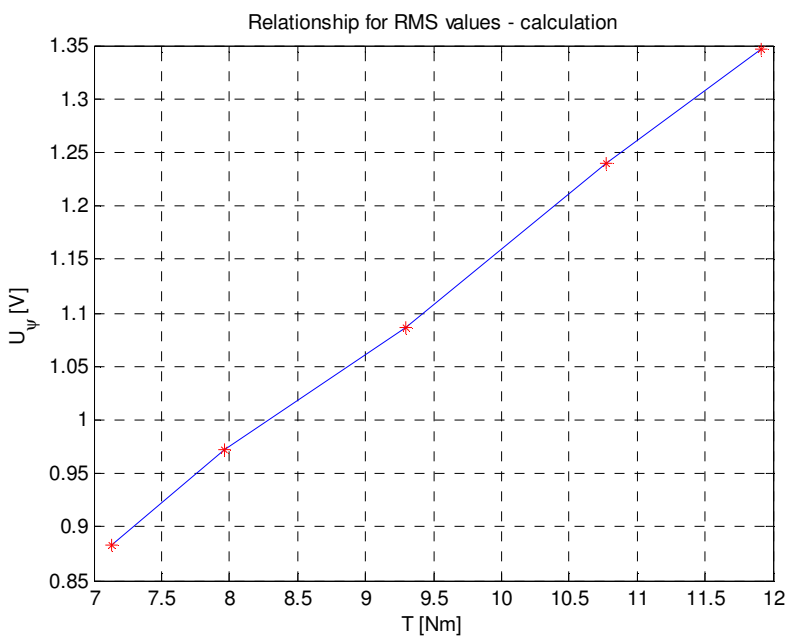

Fig. 24. Relationship between axial flux and torque.

Using the measurement coil shown in Fig. 1, a derivative of the axial flux for different motor loads was measured. About 5000 turns of the coil was wound on a resotex casing (frame) of about $150 \mathrm{~mm}$ diameter with an enamelled wire of $0.25 \mathrm{~mm}$ diameter.

The motor was loaded by the separate-excited generator. The motor and generator were connected by ROTEX flexible couplings. On the shaft, between the test motor and the load machine, a Data FLEX 22/50 torque meter was fitted, enabling a precise measurement of the load torque.

The characteristic amplitudes obtained from spectral analysis of the measured signal proportional to the derivative of the axial flux and the measured electromagnetic torque are summarized in Table 2 and graphically illustrated in Fig. 25.

In both Fig. 24. and Fig. 25, it can be observed a considerable similarity in the relationship between torque and the axial flux signal. These relationships show clearly that the load torque estimation algorithm based on the axial flow signal proved to be correct.
Table. 2. List of the characteristic features of the axial flux and the electromagnetic torque - measurements.

\begin{tabular}{|c|c|c|c|c|c|}
\hline $\begin{array}{c}\mathrm{T} \\
{[\mathrm{Nm}]}\end{array}$ & $\begin{array}{c}\text { Amp } \\
s^{*} \mathbf{f}_{\mathbf{0}} \\
{[\mathrm{V}]} \\
\end{array}$ & $\begin{array}{c}\mathbf{A m p} \\
\mathbf{f}_{0} \\
{[\mathrm{~V}]}\end{array}$ & $\begin{array}{c}\text { Amp } \\
\mathbf{f}_{\text {psh }} \\
{[\mathbf{V}]}\end{array}$ & $\begin{array}{c}\text { RMS } \\
{[\mathrm{V}]} \\
\end{array}$ & $\begin{array}{c}\mathbf{T} / \\
\mathbf{A m p} \mathbf{f}_{0} \\
{[-]}\end{array}$ \\
\hline 0.16 & 0.001 & 0.371 & 0.003 & 0.431 & 0.43 \\
\hline 4.22 & 0.007 & 0.518 & 0.004 & 0.550 & 8.15 \\
\hline 9.50 & 0.029 & 0.864 & 0.013 & 0.902 & 11.00 \\
\hline 13.81 & 0.042 & 1.197 & 0.017 & 1.226 & 11.54 \\
\hline 17.40 & 0.073 & 1.445 & 0.019 & 1.511 & 12.04 \\
\hline
\end{tabular}

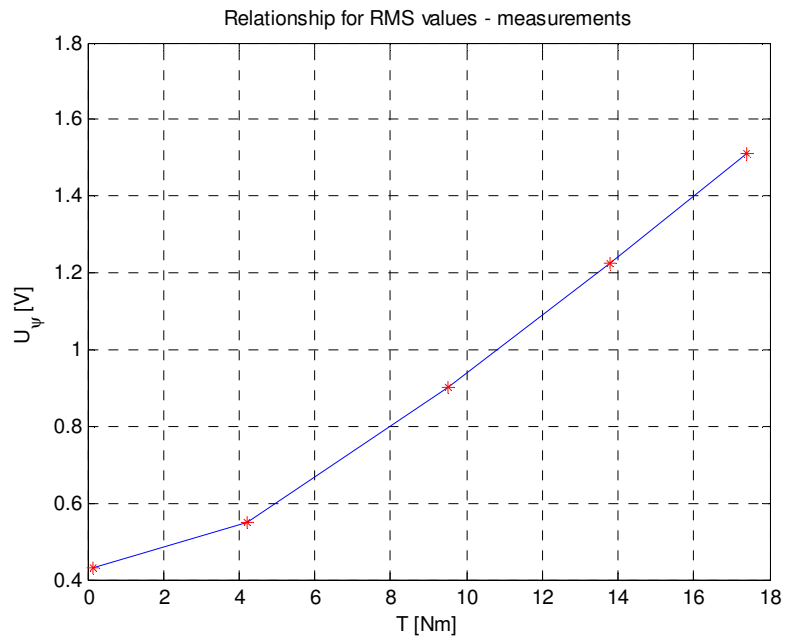

Fig. 25. Relationships between axial flux and torque measurements.

\section{Conclusions}

The results of the calculations presented here point the utility of the axial flux signal for determining the shaft torque.

The direct determination of the torque from the flux for a specific machine requires the flux versus torque characteristic as in Fig. 26. for as many work points as possible. This is possible at the test station or on the

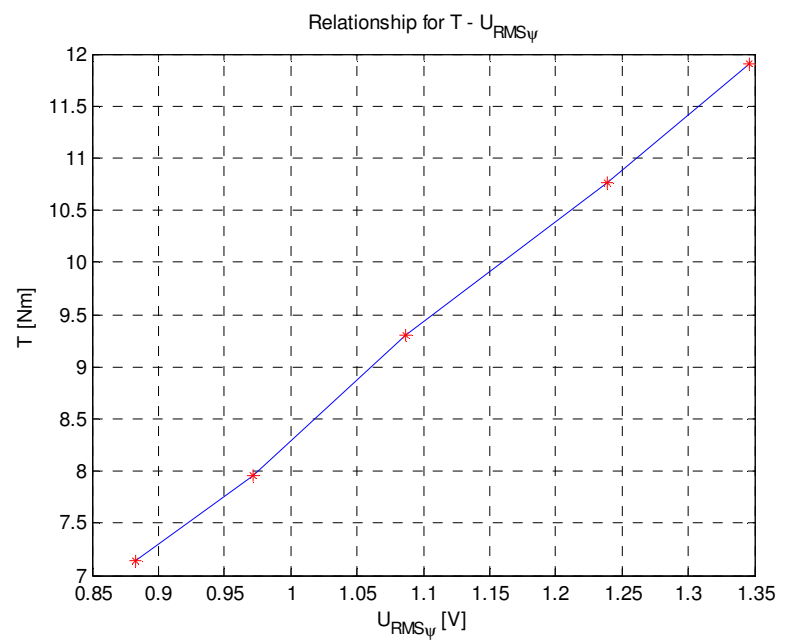

Fig. 26. Reverse relationship torque versus axial flux. 
machine workplace and makes sense when it is necessary to determine running load torque, machine efficiency or energy efficiency of the process.

Presented results of the research, which was carried out under the themes No. E-2/664/2017/DS, No. E-2/619/2016/DS, were founded by the subsidies on science granted by Polish Ministry of Science and Higher Education.

\section{References}

1. T. Assaf, H. Henao, G. A. Capolino, IEEE-ISIE, 2, 815-819 (2004)

2. A. Bobon, Tran. on Elec. Eng., 1, 3, $72-75$ (2012)

3. A. Ceban, R. Pusca, R. Romary, IEEE Tran. on Ind. Elect., 59, 5, 2082-2093 (2012)

4. P. Ewert, IEEE SME, 1-6 (2017)

5. L. Gołebiowski, M. Gołebiowski, M. Noga, J. Skwarczynski, Elektrotechnika i Elektronika, 25, 2, 147-152 (2006)

6. H. Henao, C. Demian, G. A. Capolino, IEEE Tran. on Industry Applications, 39, 2, 1272-1279 (2003)
7. W. Jarzyna, Seventh International Conference on Electrical Machines and Drives (Conf. Publ. No. 412), 141-146 (1995)

8. J. Penman, H. G. Sedding, B. A. Lloyd, W. T. Fink, IEEE Tran. on Ener. Con., 9, 652-658 (1994)

9. W. Pietrowski, Przegl. Elektr., 87, 6, 189-192 (2011)

10. W. Pietrowski, Przegl. Elektr., 88, 7b, 20-23 (2012)

11. J. Siau, A. Graff, W. Soong, N. Ertugrul, Tran. on Ind. Elect., 51, 107-121 (2004)

12. R. Pusca, R. Romary, V. Fireteanu, A. Ceban, Prog. in Electromag. Research, 50, 37-59 (2013)

13. J. Tulicki, J. Petryna, M. Sułowicz, Tech. Tran. Electrical Eng., 3-E, 99-113 (2016)

14. J. Tulicki, M. Sułowicz, J. Petryna, ISEF (2017)

15. V. Kokko, University of Oulu (2003)

16. D.G. Dorrell, W.T. Thomson, S. Roach, IEEE Tran. on Ind. App., 33, 1, 24-34 (1997)

17. L. Frosini, A. Borin, L. Girometta, G. Venchi, IEEE Int. Symp. on SDEMPED, 356-363 (2011) 